\title{
ASPECTOS PRODUTIVOS E VEGETATIVOS \\ DE MACIEIRAS CV. IMPERIAL GALA \\ INTERENXERTADAS COM EM-91
}

\author{
JOSÉ LUIZ MARCON FILHO ${ }^{2}$, LEO RUFATO ${ }^{3}$, ANDREA DE ROSSI RUFATO $^{4}$, \\ AIKE ANNELIESE KRETZSCHMAR ${ }^{4}$, CELSO ZANCAN ${ }^{6}$
}

RESUMO - A obtenção de pomares compactos, com plantas de menor vigor e alta produção, constitui uma forte tendência da horticultura atual, tendo em vista o aumento na produtividade. Uma das técnicas de redução do vigor das plantas é a interenxertia. Este estudo foi desenvolvido no pomar comercial da empresa Randon Agro Silvo Pastoril S.A. (RASIP), localizado no Estado Rio Grande do Sul, Brasil. O objetivo foi avaliar o desenvolvimento vegetativo e produtivo de macieiras cv. Imperial Gala, com diferentes comprimentos de interenxerto: $10 ; 15 ; 20 ; 25$ e $30 \mathrm{~cm}$. Os parâmetros avaliados no sétimo e oitavo anos de implantação foram os seguintes: área da seção do tronco da cultivar copa a $5 \mathrm{~cm}$ do segundo ponto de enxertia; altura da planta; volume da copa; índice de fertilidade; número de frutos por planta; produtividade estimada e eficiência produtiva. Conclui-se que o uso do interenxerto de EM-9 de $30 \mathrm{~cm}$ no porta-enxerto Marubakaido é o mais indicado para o controle do vigor de macieiras cv. Imperial Gala, garantindo a maior eficiência produtiva e frutos de maior tamanho.

Termos de indexação: Mallus domestica Borkh, redução do vigor; porta-enxerto.

\section{PRODUCTIVE AND VEGETATIVE ASPECTS OF THE IMPERIAL GALA APPLE TREES WITH EM-9 INTERSTEM IN DIFFERENT LENGTHS}

\begin{abstract}
Obtaining a compact orchard, with less vigorous plants and high production, constitutes a strong tendency in the current horticulture, aiming the raise of the productivity. One of the techniques for reducing vigor is the interstem. This study was developed in a commercial orchard of Randon Agro Silvo Pastoril S.A. (RASIP), located in Rio Grande do Sul State, Brazil. The purpose of this work was to evaluate the vegetative and productive development of apple trees cv. Imperial Gala with different lengths of EM-9 interstem. The treatments consisted of five interstem lengths: 10, 15, 20, 25, $30 \mathrm{~cm}$. The following parameters were evaluated, in the seventh and eighth year of implantation: the sectional area of the Imperial Gala $5 \mathrm{~cm}$ above the second graft point; height of the plant; the tree-head size; fertility index; the number of fruits per plant; estimated productivity and productive efficiency. The use of interstem EM-9 of $30 \mathrm{~cm}$ in the rootstock Marubakaido is the most indicated for vigor control of Imperial Gala apple trees, provides greater productive efficiency and produces bigger fruits.
\end{abstract}

Index terms: Mallus domestica Borkh, vigour reduction; rootstock

\footnotetext{
'(Trabalho 224-08). Recebido em: 29-08-2008. Aceito para publicação em: 25-04-2009. Suporte financeiro: CNPq

${ }^{2}$ Acadêmico do curso de Agronomia CAV-UDESC; Bolsista de Iniciação Científica PIBIC/CNPq Rua Humberto de Campos 1285 Bairro Coral, Ap. 301 Ed. Vicenza, Lages-SC, CEP: 88520-000 zeluizmarconfilho@desbrava.com.br

${ }^{3}$ Orientador, Dr. Fruticultura, Professor CAV/UDESC, leoruffato@yahoo.com.br

${ }^{4}$ Dra. Fruticultura, Professora FAEM/UFPel, derossiandrea@yahoo.com.br

${ }^{5}$ Orientadora, Dra. Fruticultura, Professora CAV/UDESC, a2aak@cav.udesc.br

${ }^{6}$ Engenheiro Agrônomo empresa Randon Agro Silvo Pastoril S.A. (RASIP), zancan@rasip.com.br
} 


\section{INTRODUÇÃO}

Atualmente, a área plantada com macieiras no Brasil é de 38,8 mil ha, tendo atingido a produção de 1.121,29 mil toneladas na safra de 2008 (Epagri, 2009), tornando o Brasil destaque na cultura.

Com a evolução da pomicultura no Brasil, surgiu a necessidade de aumentar a produtividade dos pomares, com a implantação em alta densidade. Segundo Pereira (1999), recomenda-se para plantios em alta densidade a utilização de porta-enxertos semivigorosos ou anões, pois, conhecendo a interdependência existente entre a copa e o porta-enxerto, facilmente se conclui que as características do portaenxerto irão influenciar no comportamento geral e final da copa.

A escolha do porta-enxerto adequado é fundamental para o sucesso da cultura. Para macieira, em alta densidade, recomenda-se utilizar porta-enxertos ananizantes (Denardi, 2002). Os porta-enxertos ananizantes, apesar desta característica positiva, apresentam o inconveniente de formar um sistema radicular muito superficial, o que exige sistema de sustentação para as plantas (Denardi, 2002), aumentando o custo de implantação do pomar.

Para a cultura da macieira em alta densidade, o porta-enxerto EM-9 (East Malling) vem sendo o mais utilizado, porém apresenta fraca ancoragem radicular e é suscetível ao pulgão- lanígero (Eriossoma lanigerum - Hausmann). Uma solução para estes problemas é utilizar o EM-9 como filtro do porta-enxerto Marubakaido, através da técnica de interenxertia. Segundo Pereira (1999), a redução do porte final da planta pode ser obtida através do uso de um interenxerto ananizante entre o porta-enxerto vigoroso e a cultivar copa.

A interenxertia, segundo Hartmann et al. (1990), consiste na utilização de um fragmento de caule intermediário ou filtro compatível entre o porta-enxerto e o enxerto, que pode influenciar no desenvolvimento da copa e das raízes. Esta é uma técnica que, em regra, tem o objetivo de diminuir o vigor das plantas, aumentar a eficiência produtiva e melhorar as qualidades das frutas.

O uso da técnica de interenxertia do EM-9 sobre o Marubakaido reúne as principais características dos dois porta-enxertos, ou seja, o sistema radicular profundo e a resistência ao pulgão-lanígero e a podridão do colo do Marubakaido, e as características ananizantes, de indução de precocidade de frutificação, de altas produções e qualidade da fruta do EM-9 (Grellmann, 1988; Tsuneta \& Hauagge, 1988). Nas áreas de replantio, por exemplo, está sendo recomendada a utilização do porta-enxerto
Marubakaido com interenxerto de EM-9 ou EM-7, devido a problemas de contaminações de solo e de alelopatia (Embrapa, 1998).

A interenxertia em macieira é recomendada por diversos autores (Embrapa, 1998; Pereira, 1999; Rufato et al., 2001), porém a influência do comprimento do interenxerto sobre as características da planta não está completamente esclarecida.

De acordo com Barritt (1992), o comprimento do interenxerto varia de 10 a $30 \mathrm{~cm}$ para a redução do vigor da planta, e pode ser utilizado com até $60 \mathrm{~cm}$ para outras finalidades, como obtenção de resistência à injúria pelo frio ou podridão do colo.

A técnica da interenxertia já está sendo usada em outras culturas, como pessegueiro (Rufato et al., 2006; Scarpare Filho et al., 2000; Telles et al., 2006), pereira (Baciu et al., 2008), laranjeira 'Pêra' (Girardi \& Mourão Filho, 2006) e mangueira (Velosa, 2004).

O objetivo deste trabalho foi avaliar aspectos produtivos e vegetativos de plantas de macieira cv. Imperial Gala, interenxertadas com diferentes comprimentos de EM-9, sobre o porta-enxerto Marubakaido.

\section{MATERIAL E MÉTODOS}

O experimento foi conduzido no pomar comercial da empresa Randon Agrosilvopastoril S.A. (RASIP), em Vacaria-RS, situado a aproximadamente $955 \mathrm{~m}$ de altitude, apresentando como coordenadas geográficas $50^{\circ} 56^{\prime} 02^{\prime \prime}$ de latitude sul e $28^{\circ} 30^{\prime} 14^{\prime \prime}$ de longitude oeste. O solo da área experimental é classificado como Latossolo Bruno distrófico.

O clima de Vacaria, conforme a classificação de Köeppen (1948), é do tipo Cfb: temperado úmido, com temperatura média anual de $15,5^{\circ} \mathrm{C}$, média das mínimas de $10,2^{\circ} \mathrm{C}$ e média das máximas de $22,3^{\circ} \mathrm{C}$. A precipitação pluvial média anual é de $1.412 \mathrm{~mm}$, em 98 dias de chuva. A média de umidade relativa do ar é de $79 \%$, e o somatório médio de horas de frio, inferior a $7^{\circ} \mathrm{C}(\mathrm{HF})$, de maio a agosto, é de 471 horas, e de maio a setembro de 982 horas. O número médio de unidades de frio (UF), pelo método da Carolina do Norte Modificado, é de 1.561 UF. A radiação solar global média é de $15,7 \mathrm{MJ}^{-2} \cdot$ dia $^{-1}$ (Instituto de Pesquisas Agronômicas, 1989).

O pomar foi instalado no ano de 1999, com espaçamento de 4,5 m x 1,25 m. As mudas foram obtidas realizando duas enxertias de garfagem em dupla fenda. O sistema de condução utilizado foi em líder central, e os tratos culturais (poda, superação de dormência, raleio de frutos e tratamentos fitossanitários) foram realizados pela empresa de acordo com 
as normas da Produção Integrada de Maçã.

Os tratamentos constaram de cinco comprimentos de interenxerto de EM-9 $(10 ; 15 ; 20 ; 25$ e 30 $\mathrm{cm})$, ligando o porta-enxerto Marubakaido à cultivar copa Imperial Gala.

O delineamento experimental adotado foi o de blocos ao acaso, com três repetições e dez plantas por parcela. Os resultados foram submetidos à análise de regressão polinomial.

Nos anos de 2006 e 2007, foram avaliadas as seguintes variáveis: a) área da seção do tronco $\left(\mathrm{cm}^{2}\right)$ da cultivar copa, obtida através da média das medidas longitudinal e transversal à linha de plantio do diâmetro do tronco, calculada através da fórmula $\mathrm{A}=\left(\pi \mathrm{d}^{2}\right) / 4$, onde $\mathrm{d}=$ diâmetro; b) altura da planta (m), obtida pela medida a partir do seu ponto de enxertia; c) volume da copa $\left(\mathrm{m}^{3}\right)$, obtido pelas medidas da largura e espessura da copa e a altura a partir do ponto de inserção do primeiro ramo no tronco; d) índice de fertilidade, através da relação direta entre o número de gemas floríferas e o comprimento do ramo; e) número de frutos por planta, obtido pela contagem visual dos frutos, uma semana antes da colheita; f) produtividade estimada $\left(\mathrm{t} \mathrm{ha}^{-1}\right)$, calculada pela multiplicação do peso total colhido por planta pelo número de plantas existentes em um hectare, de a cordo com o espaçamento utilizado $(4,5 \times 1,25 \mathrm{~m}=$ $1.777,77$ plantas.ha $\left.{ }^{-1}\right)$; g) eficiência produtiva $\left(\mathrm{kg} \cdot \mathrm{m}^{-3}\right)$, calculada através da relação entre o peso da produção e o volume da copa; h) calibre do fruto (mm), obtido pelo diâmetro transversal, medido com paquímetro manual.

\section{RESULTADOS E DISCUSSÃO}

Com relação à área da seção do tronco, o comprimento do interenxerto teve influência significativa, com decréscimo linear nos dois anos (Figura 1). Rossi et al. (2003), estudando a cultivar Imperial Gala interenxertada com EM-9, observaram que a área da seção do tronco apresentava comportamento quadrático em relação ao comprimento do interenxerto. Diferentemente, neste trabalho, pode-se observar que, proporcionalmente, quanto maior o comprimento do interenxerto de EM-9 menor era a área da seção do tronco.

A redução da área da seção do tronco, provavelmente, está relacionada a sintomas de incompatibilidade fisiológica. Segundo Ryugo (1993), a incompatibilidade fisiológica tem como sintoma redução do crescimento longitudinal da união. Para Westwood (1982), esta noção apoia-se principalmente no fato de que muitas uniões incompatíveis mostram um sobre o crescimento do enxerto.
A altura das plantas decresceu linearmente com a redução do comprimento do interenxerto (Figura 2-A), concordando com o observado por Pereira (1999). O volume da copa apresentou comportamento semelhante à altura, influenciado pelo comprimento do interenxerto, decrescendo linearmente nos dois anos (Figura 2-B). Da mesma forma, observou-se redução no desenvolvimento dos ramos com o aumento no comprimento do interenxerto, apresentando os ramos de plantas com interenxerto de $30 \mathrm{~cm}$ maior número de esporões, enquanto com filtro de $10 \mathrm{~cm}$ apresentavam ramos longos e maior número de brindilas (Figura 3).

A redução do crescimento das plantas interenxertadas com EM-9 pode ser regulada por dois mecanismos diversos, quais sejam, a redução da translocação de carboidratos para a copa no ponto de enxertia, ou pela redução de hormônios de crescimentos produzidos nas raízes, que ficam retidos no filtro de EM-9, ocasionada por certa incompatibilidade. Para Ryugo (1993), a base fisiológica da redução do crescimento das plantas está relacionada com o transporte ascendente de nutrientes inorgânicos, a restrição do transporte descendente pelo floema e alguma perturbação fisiológica.

Para Rozpara et al. (1990), o interenxerto modifica os teores de nutrientes minerais na copa das plantas e, segundo os autores, a redução no teor do K pode ser a causa da redução do crescimento vegetativo.

O índice de fertilidade cresceu linearmente com o aumento do comprimento do interenxerto nos dois anos (Figura 4), diferentemente dos dados encontrados por Rossi et al. (2003), que observaram tendência quadrática para esta variável. Tal comportamento deve-se, provavelmente, ao menor crescimento vegetativo da planta que, consequentemente, melhora o balanço entre a parte vegetativa e a reprodutiva, como resposta à menor translocação ascendente e descendente da seiva (Hartmann et al., 1990).

O número de frutos por planta diminuiu proporcionalmente com o aumento do comprimento do interenxerto (Figura 5-A). Com a diminuição da produção por planta, provocada pelo aumento do comprimento do filtro, a produtividade estimada por hectare foi igualmente afetada; no entanto, na safra de 2007/08 observou-se um comportamento quadrático, com o ponto de mínima no comprimento teórico de $22,2 \mathrm{~cm}$ do interenxerto (Figura 5-B). A menor produtividade observada com $22,2 \mathrm{~cm}$ de filtro indica que poderá ser trabalhado um comprimento de filtro maior ou menor, dependendo do resultado final desejado pelo produtor, uma vez que um comprimento 
maior proporcionará menor número de frutos com maior tamanho, e um comprimento inverso.

A eficiência produtiva aumentou linearmente na safra de 2006/07, e com um comportamento quadrático, com ponto de mínima no comprimento do interenxerto de 15,6 cm, na safra de 2007/08. Porém, nos dois anos, a maior eficiência produtiva foi proporcionada pelo interenxerto de $30 \mathrm{~cm}$ (Figura 6-A). Assim, copas de plantas menos vigorosas, com filtros de maior comprimento, podem produzir mais que copas de plantas mais vigorosas.

Em relação à variável calibre do fruto, não houve diferença significativa na safra de 2006/07; no entanto, na safra de 2007/08, observou-se comportamento quadrático, com ponto de mínima de $17,4 \mathrm{~cm}$ de comprimento do interenxerto (Figura 6-B), e frutos de maior tamanho com $30 \mathrm{~cm} \mathrm{de}$ comprimento.
De maneira geral, o aumento do comprimento do filtro reduziu o crescimento das plantas, tornando as copas mais compactas e melhorou o tamanho dos frutos. Esta redução no porte da planta, além de aumentar a eficiência produtiva, possibilita a adoção de espaçamentos mais reduzidos e maior facilidade nos tratos culturais, principalmente nas operações de poda, raleio, tratamentos fitossanitários e colheita.

Segundo Hartmann et al. (1990), os efeitos do interenxerto podem ser considerados indiretos, uma vez que fatores internos, como circulação de água, nutrientes e reguladores vegetais são os que realmente são afetados pelo filtro, provocando respostas sobre o crescimento da planta, florescimento e frutificação.

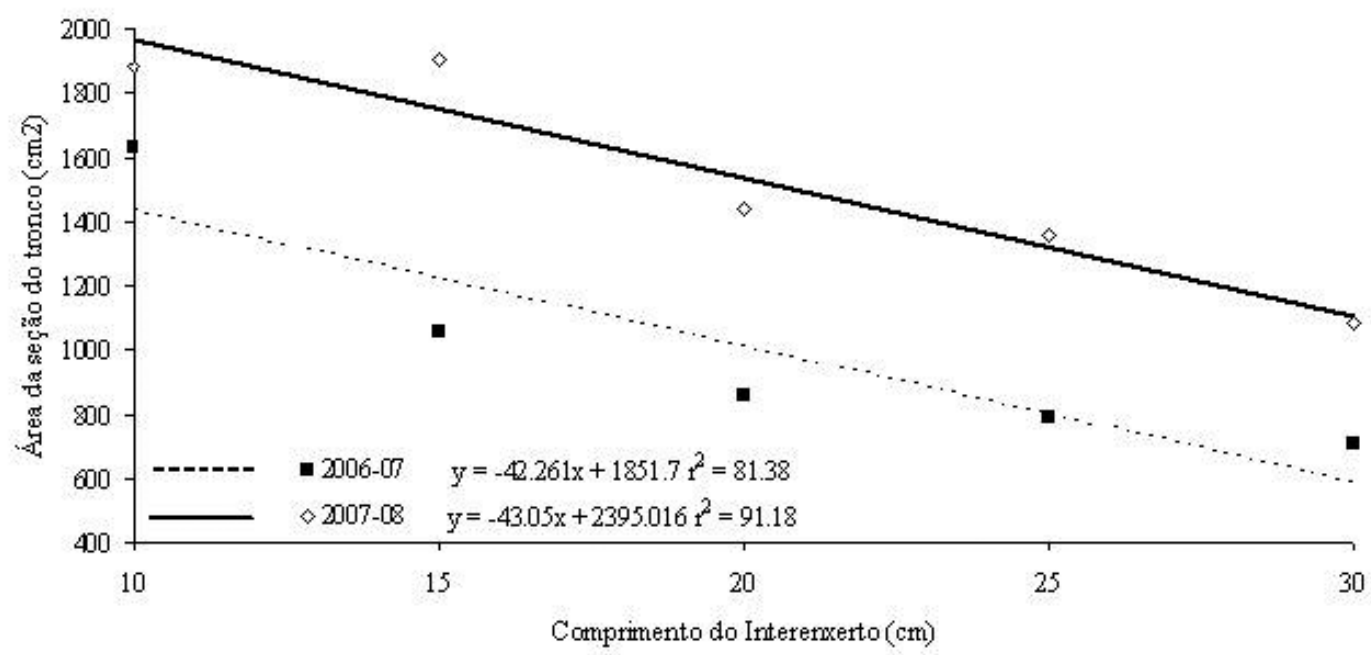

FIGURA 1 - Influência do comprimento do interenxerto de EM-9 na área da seção do tronco a $5 \mathrm{~cm}$ acima do ponto de enxertia da macieira cv. Imperial Gala sobre porta-enxerto Marubakaido. Lages, 2008 . 

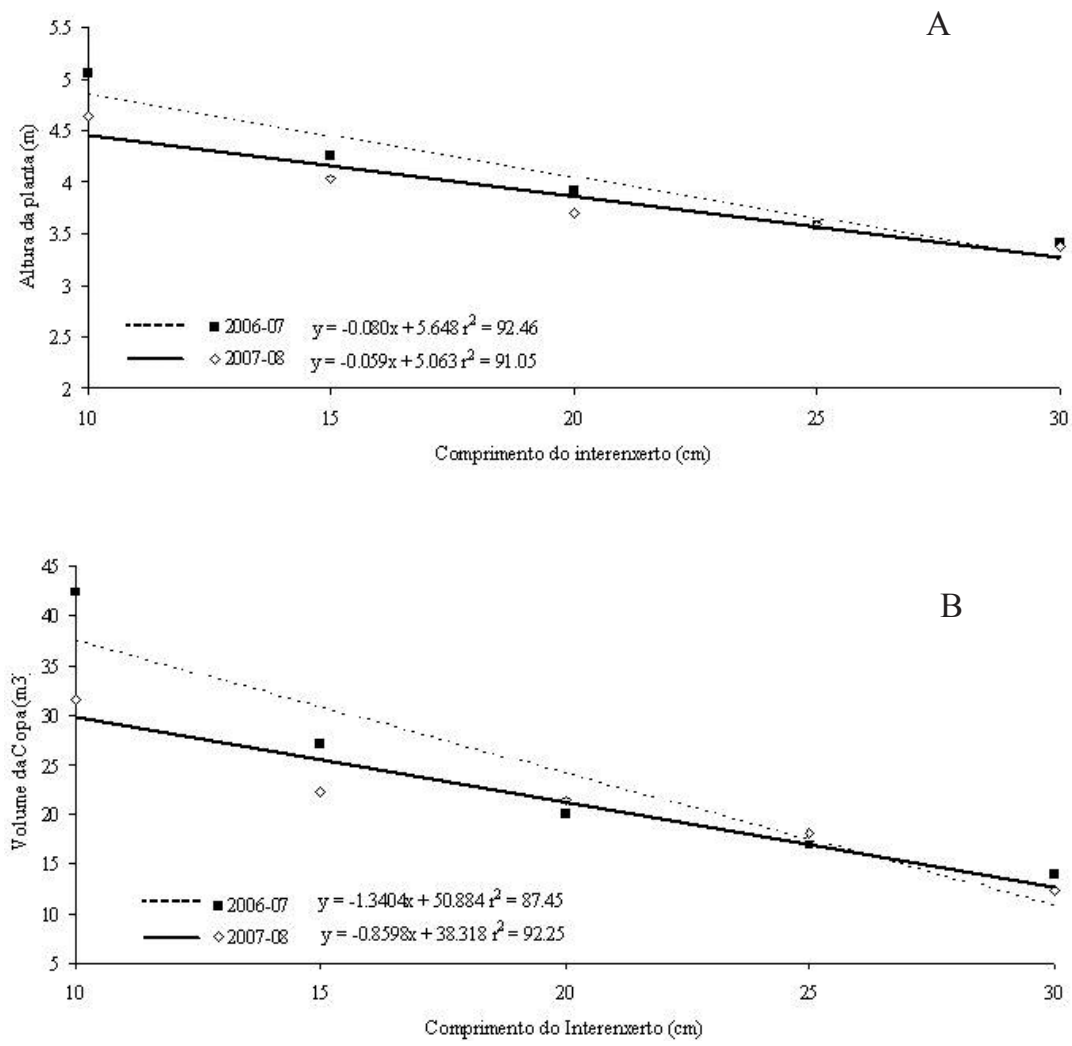

FIGURA 2 - Influência do comprimento do interenxerto de EM-9 na altura da planta (A) e no volume da copa (B) da macieira cv. Imperial Gala sobre porta-enxerto Marubakaido. Lages, 2008.

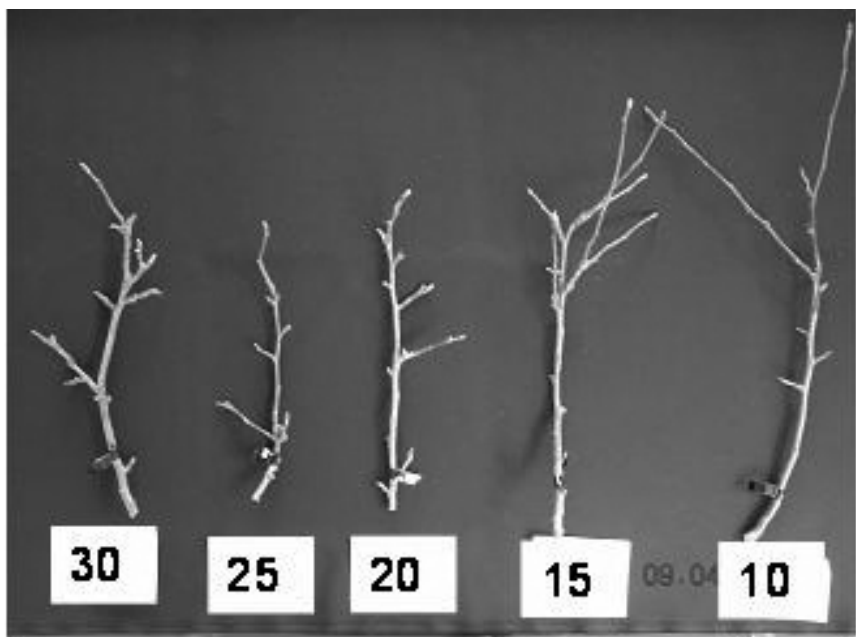

FIGURA 3 - Estrutura dos ramos de acordo com o comprimento do Interenxerto de EM-9 sobre o portaenxerto Marubakaido em macieira cultivar Imperial Gala. Lages, 2008. 


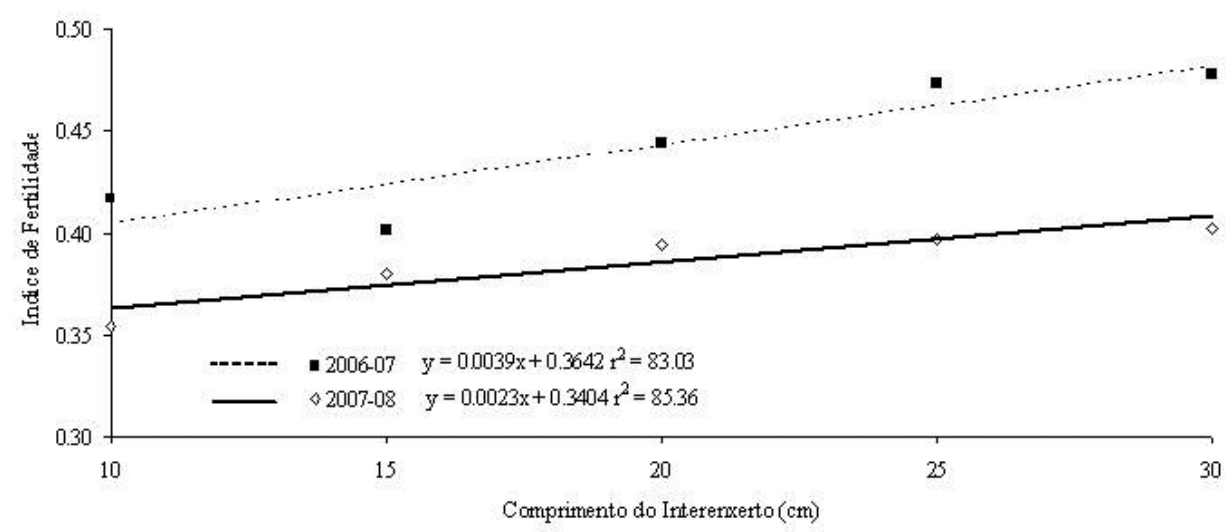

FIGURA 4 - Influência do comprimento do interenxerto de EM-9 no índice de fertilidade da macieira cv. Imperial Gala sobre porta-enxerto Marubakaido. Lages, 2008.
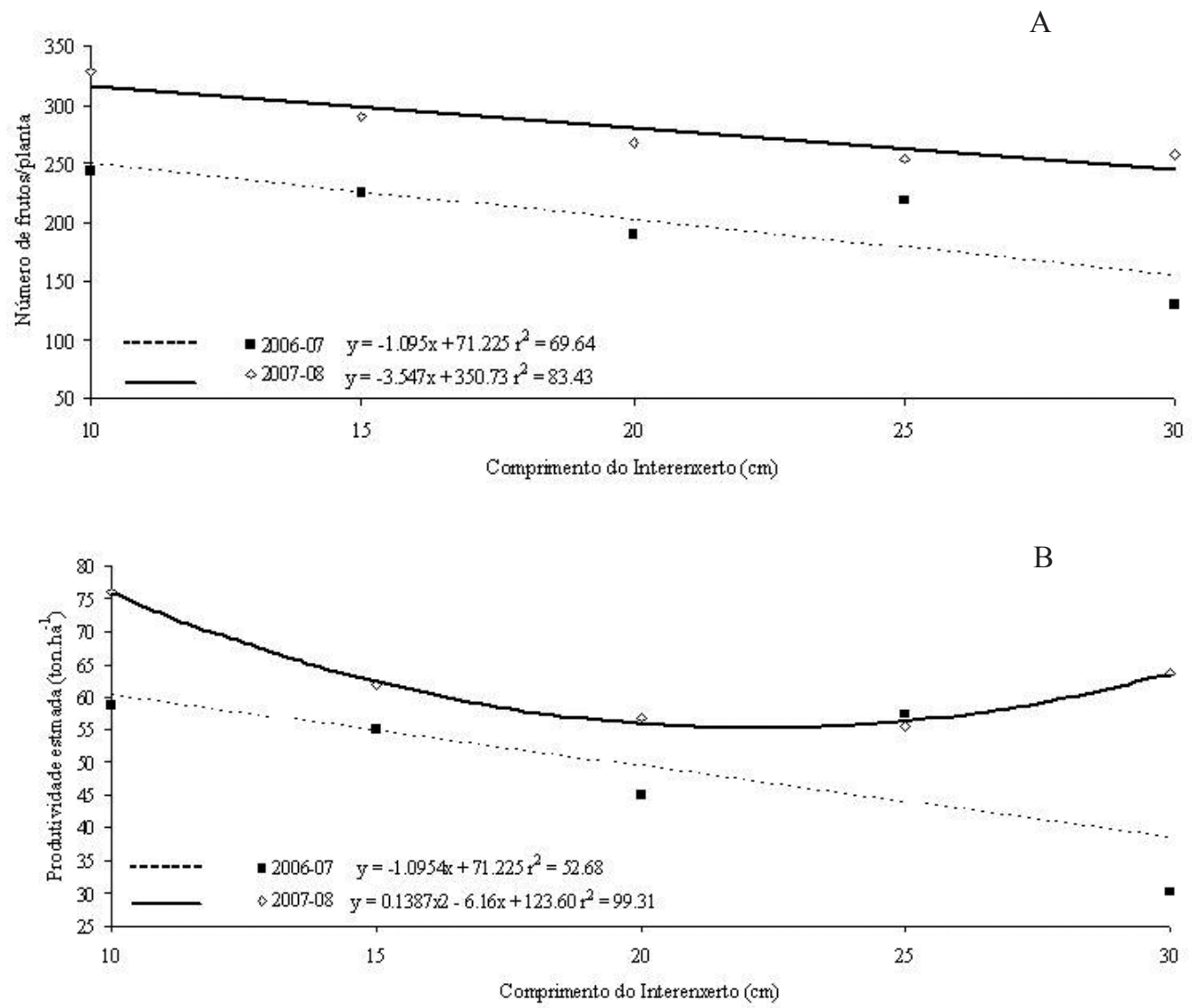

FIGURA 5 - Influência do comprimento do interenxerto de EM-9 no número de frutos por planta (A) e produtividade estimada (B) em macieira cv. Imperial Gala sobre porta-enxerto Marubakaido. Lages, 2008. 

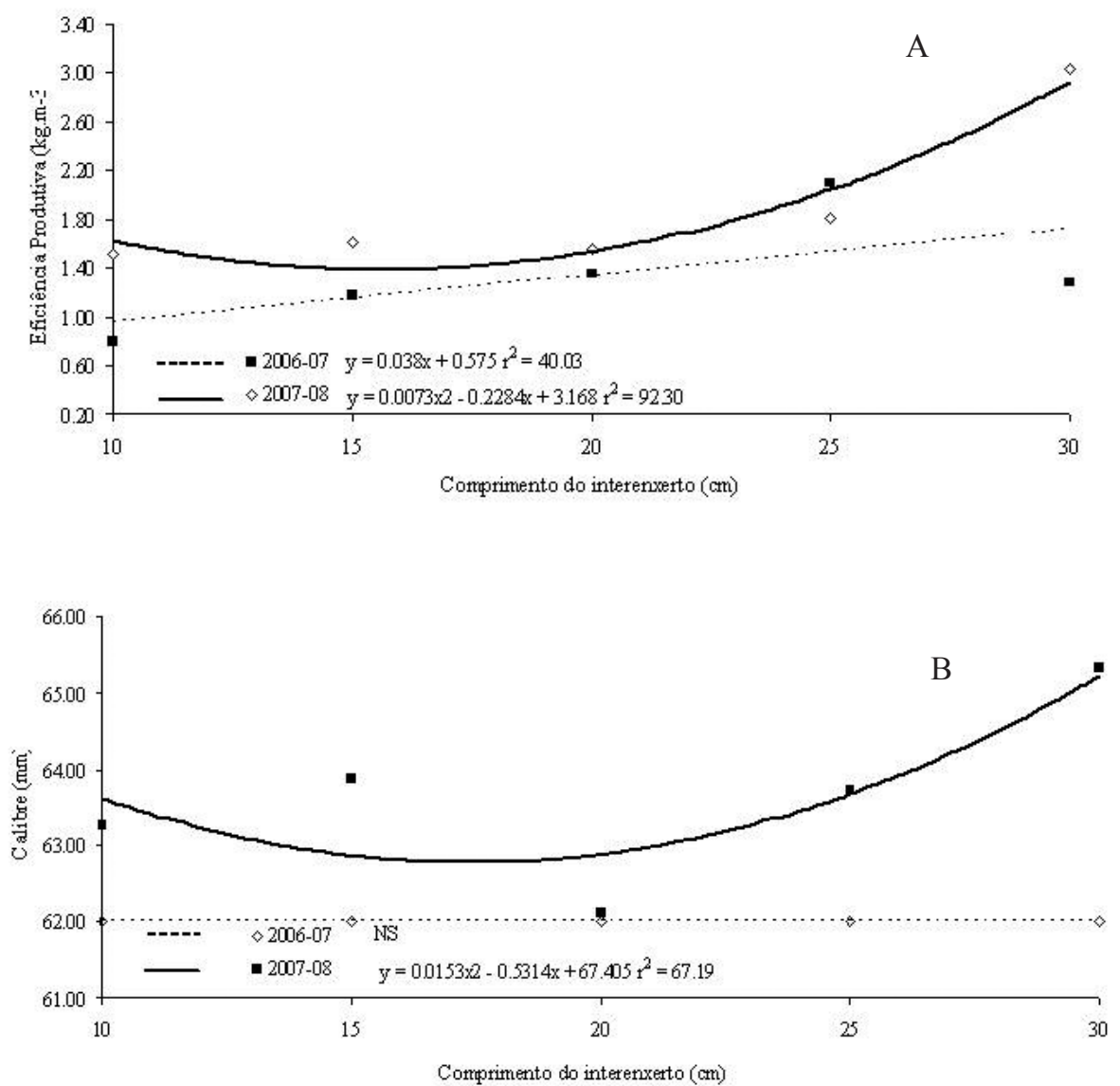

FIGURA 6 - Influência do comprimento do interenxerto de EM-9 na eficiência produtiva (A) e calibre do fruto (B) da macieira cv. Imperial Gala sobre porta-enxerto Marubakaido. Lages, 2008.

\section{CONCLUSÃO}

O uso do interenxerto de EM9 de $30 \mathrm{~cm}$ no porta-enxerto Marubakaido é o mais indicado para controle do vigor de macieiras cv Imperial Gala, proporcionando maior eficiência produtiva e frutos de maior tamanho.

\section{REFERÊNCIAS}

BACIU, A.; ACHIM, G.; COSMULESCU, S. Opportunities for reducing the time necessary to obtain tress with interstocks in pear tress. Acta Horticulturae, Wageningen, n. 800, p. 731-736, 2008.

BARRITT, B.H. Intensive orchard management. Washington: Good Fruit Grower, 1992. 212 p.

DENARDI, F. Porta-enxertos. In: EPAGRI. A cultura da macieira. Florianópolis, 2002. p.169-227
NACHTIGAL, G.R.; SANHUEZA, R.M.V.; PROTAS, J.F.S. (Ed.). Normas para produção integrada de maçãs no Brasil. In: REUNIÃO SOBRE O SISTEMA DE PRODUÇÃO INTEGRADA DE MACIEIRA NO BRASIL, 1., 1998, Bento Gonçalves. Anais... Bento Gonçalves: EMBRAPA - Uva e Vinho, 1998. p. 30-40

EPAGRI. Tabelas de produção. In: CEPA - Centro de Socioeconomia e Planejamento Agrícola. Disponível em: $<$ http://www.cepa.epagri.sc.gov.br $>$. Acesso em: 30 jan. 2009.

GIRARDI, E.A.; MOURAO FILHO, F. de A.A. Production of interstocked 'Pera' sweet orange nursey trees on 'Volkamer' lemon and 'Swingle' citrumelo rootstocks. Scientia Agrícola, Piracicaba, v. 63, n. 1, p. 5-10, 2006. 
GRELLMANN, E.O. Produção de mudas de macieira. Porto Alegre: FEPAGRO, 1988. p. 15-19. (Boletim Técnico, 31)

HARTMANN, N.T.; KESTER, D.E.; DAVIES JUNIOR, F.T. Plant propagation: principles and practices. 5 ed. Englewood Cliffs: Regents/PrenticeHall, 1990. 647 p.

INSTITUTO DE PESQUISAS AGRONÔMICAS. Seção de Ecologia Agrícola. Atlas agroclimático do Estado do Rio Grande do Sul. Porto Alegre, 1989. v.1, 102 p.

KÖPPEN, W. Climatologia. México: Fundo de Cultura Econômica, 1948. 478 p.

PEREIRA, A.J. Influência de interenxertos sobre o vigor e produtividade de plantas de macieira cvs. Gala e Fuji. Jornal da Fruta, Lages, n. 65, p. 10, 1999.

ROSSI, A.; de; RUFATO, L.; KERSTEN, E.; ZANCAN, C. Comportamiento vegetativo del manzano Imperial Gala con diferentes longitudes de intermediario. Información Técnica Económica Agraria, Zaragoza, v. 99, n. 1, p. 140-146, 2003.

ROZPARA, E.; GRZYB, Z.S.; PHARIS, R.P. The influence of dwarfing interstock on the distribution on metabolismo f xylem-applies [3H] gibberellin A4 in apple. Acta Horticulturae, Wageningen, n. 274, p. 405-412, 1990.

RUFATO, L.; ROSSI, A.; de; GIACOBBO, C.L.; FACHINELLO, J.C.; GOMES, F.R.C. Intergrafting to control vigor of 'Jubileu' peach. Acta Horticulturae, Wageningen, n. 713, p. 231-236, 2006.
RUFATO, L.; ROSSI, A.; de; KERSTEN, E; ZANCAN, C. Redução do crescimento inicial de mudas de macieira (Malus domestica Borckh.) Imperial Gala interenxertadas com EM9. Revista Brasileira de Fruticultura, Jaboticabal, v. 23, n. 1, p. 172-174, 2001.

RYUGO, K. Fruticultura: ciência y arte. México: AGT, 1993. 460 p.

SCARPARE FILHO, J.A.; KLUGE, R.A.; VICTÓRIA FILHO, R.; NETO, J.T.; JACOMINO, A.P. Comportamento de duas cultivares de pessegueiro com interenxerto da ameixeira 'Januária'. Pesquisa Agropecuária Brasileira, Brasília, v. 35, n. 4, p. 757-765, 2000.

TELLES, C.A.; BIASI, L.A.; NETO, U.R.M.; PETERS, E. Sobrevivência e crescimento de mudas de pessegueiro interenxertadas. Revista Brasileira de Fruticultura, Jaboticabal, v. 28, n. 2, p. 297-300, 2006.

TSUNETA, M.; HAUAGGE, R. Cultivares e porta-enxertos. In: IAPAR. A cultura da macieira no Paraná. Londrina, 1988. p. 22-33. (Circular Técnica, 50)

VELOSA, M.E. da C.; VASCONCELOS, L.F.L.; SOUZA, V.A.B. Interstock effect on the vegetative growth of three mango cultivars at Teresina, Piauí state, Brazil. Acta Horticulturae, Wageningen, n. 645 , p. 223-226, 2004

WESTWOOD, N.H. Fruticultura de zonas templadas. Madrid: Mundi-Prensa, 1982. 461p. 